\title{
A Study on the Changes in Reading Styles of College Students from the Borrowing Volume of Paper Books
}

\author{
Xiaoqing Wang \\ Library of Shandong Institute of Business and Technology \\ Yantai, Shandong 264005
}

\begin{abstract}
Fundamental changes have taken place in the reading habits of college students in the digital media age. This paper, through the statistical analysis of the borrowing volume of paper books in Shandong Institute of Business and Technology for the last five years, finds out the changes and status of reading habits and contents of college student, and suggests that colleges and universities should organize various reading promotion activities and erect a reading platform in accordance with the characteristics of college students. In this way, the students can be guided to read in a correct and efficient way.
\end{abstract}

\section{STATISTICAL ANALYSIS OF THE BORROWING VOLUME DATA OF PAPER BOOKS}

Through the statistical analysis of the borrowing volume of books of the library of Shandong Institute of Business and Technology during January 2013 - June 2018, this paper finds that the changes mainly lie in the reading habits of the readers. In this way, the students can be guided to read in a correct and efficient way.

Keywords-College student readers; Borrowing volume of paper books; Reading mode; Reading guidance

TABLE I. STATISTICAL TABLE OF BORROWING AMOUNT OF PAPER BOOKS DURING 2013 -2018 (JANUARY-JUNE)

\begin{tabular}{|c|c|c|c|c|c|c|}
\hline Year & 2013 & 2014 & 2015 & 2016 & 2017 & 2018 (January-June) \\
\hline Borrowing volume & 215811 & 191566 & 145564 & 122457 & 107305 & 49027 \\
\hline
\end{tabular}

TABLE II. THE PROPORTION OF LITERATURE BOOKS IN THE TOTAL BORROWING VOLUME DURING 2013 -2018 (JANUARY-JUNE)

\begin{tabular}{|c|c|c|c|c|c|c|}
\hline Year & 2013 & 2014 & 2015 & 2016 & 2017 & 2018 (January-June) \\
\hline Literature borrowing volume & 22785 & 23089 & 17002 & 14028 & 15118 & 6451 \\
\hline Total borrowing volume & 215811 & 191566 & 145564 & 122457 & 107305 & 46027 \\
\hline Proportion & $10.6 \%$ & $12 \%$ & $11.7 \%$ & $11.4 \%$ & $14 \%$ & $14 \%$ \\
\hline
\end{tabular}

From the statistical data of the above two tables, we can see that the total borrowing volume of paper books is declining year by year. It's 22785 volumes in 2013 and 107305 volumes in 2017 , declined by $50 \%$, and it's only 46027 volumes in the first half of 2018. But the decline rate of the borrowing volume of literature books is far below the decline rate of the total borrowing volume. It declines from 22785 volumes in 2013 to 15118 volumes in 2017 , declined by $33 \%$, and the proportion of borrowing volume of literature books in the total borrowing volume is rising year by year, from $10.6 \%$ in 2013 to $14 \%$ in 2017 and in the first half of 2018, and the borrowing volume of literature books ranked the first in all kinds of books. For students of non-literature majors, literature books are mostly leisure books rather than professional books. According to the description of the borrowing volume of books, the borrowing volume of literature, character analysis and history books of students of Shandong Institute of Business and Technology is large, while the borrowing volume of philosophy and professional books is small; among the literature books, Chinese literature books are borrowed more than foreign books; the relatively simple popular novels in Chinese literature are borrowed more, while classic works such as A Dream in Red Mansions does not have a large amount of reading. Professional books are mainly concentrated in the fields of Marxism Leninism, management, law and other fields, in which the time characteristics of management and legal books are prominent, mainly before the examination; the borrowing volume of students majoring in information technology is large. The borrowing of professional books is before the examination, such as grade four and six English test. During the preparation stage of graduation thesis, during the period teachers of specialized courses assign homework or borrowing books according to the period specified by professional teachers, the borrowing volume will increase significantly. In general, students' reading of professional books is in a completely passive state, rather than active demand. 


\section{READING HABITS OF COLLEGE STUDENTS}

With the rapid development of information technology, various electronic readers, Kindle, mobile phone APP, computer and all kinds of listening and video learning methods have appeared, and a large number of electronic books, electronic documents and databases are ordered every year in the library, and the use of electronic resources is not affected by time and place, which is convenient and quick. They have incomparable advantages of paper books and these factors have greatly affected the number of paper books borrowed by readers.

This fast-food way of reading and learning usually divides a whole thing into fragmentation pieces, the so-called "fragmentation reading". The advantage of "fragmentation reading" is that it can improve the utilization rate of "fragmentation" time. Because of the quickening pace of life, the modern people have little time to sit down to read the complete books, so they choose to do "fragmentation reading" in the fragmentation time, which greatly improves the utilization rate of fragmentation time. Secondly, "fragmentation reading" can speed up the acquisition and transmission of information. The development of mobile Internet technology and the popularization of mobile terminal equipment make "fragmentation reading" possible, coupled with the development of interactive platform and self-media, readers can spend less time and get more information. After receiving this information, readers can share information according to their hobbies, which further speeds up the transmission of information. Finally, "fragmentation reading" can guide people to "deep reading". Although "fragmentation reading" has brought great convenience to people in information acquisition, its drawbacks are also obvious. 1. The randomness of "fragmentation reading". In the Internet world, information is complex and diverse. People's attention to information is basically a cursory glance, which is very arbitrary, and cannot even be called reading. 2. The shallow nature of "fragmentation reading". When people talk about "fragmentation reading", they will inevitably mention "shallow reading". The direct consequence of "shallow reading" is to swallow the whole thing, to know little, and to simply understand the information. 3. "Fragmentation reading" is easy to create mental inertia. Due to the proliferation of network information, during "Fragmentation reading", the readers' ability to identify information is decreasing gradually, and they are lack of deep thinking on problems. Readers are more passively receiving information, and this fragmentation information can only form a rough outline in the brain, then fade or even disappear. This meaningless "fragmentation reading" is very easy to create mental inertia [1]. To a certain extent, these reading results in the distraction of students' reading, the reduction of imagination, the lack of thinking depth and the weakening of creativity.

\section{FACE THE REALITY AND GUIDE CORRECTLY}

"Fragmentation reading" is relatively consistent with the reading habits of college students. According to the results of the fifteenth national reading survey: more than half of adult people in China prefer digital reading: Among them, the young and middle-aged groups under the age 49 are the main groups of digital reading behavior; Audio reading has become a new growth point of national reading. The listening rate of adult citizens is $22.8 \%$. Mobile audio APP platform has become the mainstream choice of listening to books. The proportion of deep book reading behavior is low, and $21.7 \%$ of netizens take "reading online books and newspapers" as one of the main online activities [2].

College students belong to the youth group under the age of 49 , and they are the main group of digital reading behavior. The university library gives continuous guidance to the college student reader group, makes them interested in a certain field of knowledge, and then completes the transformation from "shallow reading" to "deep reading". Through paper reading, college students mainly use teaching books, examination guidance books and other textbooks and teaching aids; Correspondingly, under the influence of the new media, the reading of professional periodicals and books such as classic academic works, popular science books and academic periodicals is relatively less. Internet reading, mobile phone reading and other forms of digital reading have gradually become an important way for college students to acquire information and learn knowledge. At the same time, network entertainment, communication and network consumption and other network activities also occupy a very large proportion of time. Based on the advantages of quick search, convenient carrying, convenient use, low cost and diversified channels, electronic life and digital reading have gradually become a new way of life and reading learning habits of college students. In view of the characteristics of the present college students, the library of Shandong Institute of Business and Technology mainly publicize the paper books of the library from the following main aspects to the readers: first, the library regularly releases the "new book guide" through the Newspaper of Shandong Institute of Business and Technology; second, use the "new book recommendation" column in the library's internal journal Information Garden; third, use the "new book bulletins" in the library's bibliographic retrieval system; fourth, use the LED screen in the library, the publicity board in the library, the propaganda frame to recommend new books; fifth, use the "one hour lecture", "entrance education for new students" and other lectures and training; sixth, embed reader information literacy education in the classroom; seventh, actively use the library's home page, the library's WeChat official account, the campus network digital Shanshang system, the campus network internal mailbox and other digital channels to publicize and promote the library's latest resources, lectures, activities and other information.

Chinese library classification number: G645. 
The library of Shandong Institute of Business and Technology carries out reading promotion every year around the "World Reading Day". Every year, it carefully designs activity themes (such as "Read in Shanshang, Enjoy the Reading Time", "Book Fragrance Overflows Shanshang, Devote Youth to Your Dreams"), and develops the activity plan. For example: Reading Talent: the "top ten reading stars" of Shandong Institute of Business and Technology over the years; Happy Sharing, Enlightening the Mind: solicit articles for the theme with award; Xiemeng Fasheng: Reciting classic recitation activities, etc. The library also actively publicizes the activities through the League committee's "Dream Space", the library homepage, and WeChat. There are a large number of participants, and the effect is very good. For example, during the library's "you choose books, I pay the bill" reader recommendation activity on May 15-16, 2017. During the activity, a total of more than 7000 new books were exhibited, and about 500 people participated in this activity.

\section{SUGGESTIONS}

It is hoped that professional teachers should guide their students to read more books, encourage them to borrow books from the library, including professional books, and also deep literature, philosophy, and economic books. For students, professional teachers' words are more effective, while the advice of ordinary teachers may not be enough. Teacher Lv Zhengfang also suggested: at present, the students' participation in various reading activities should be improved, and students' participation should be higher if they can be given more innovative credits. The library should give full play to the role of the library's student management committee, actively contact the school's league committee, increase the publicity and holding of the activities, and strive for the participation and cooperation of the students' associations (such as Mu Feng Literature Society and Shanshang Micro Film Association). Students are the main participants of the activities, and planning and arranging activities from the perspective of students will arouse students' enthusiasm.

University libraries can actively unite the League Committee and the student associations to organize the digital reading activities regularly, enrich the college students' afterschool life, guide the scientific and healthy reading way, and deepen the establishment and cultivation of the digital reading literacy. Students who have experienced different stages of examination-oriented education are more locked in the blackboard under the traditional educational model and the inherent educational framework of the classroom. Facing the digital platform with new media as the carrier, the traditional way of receiving and obtaining information is subverted. The rich reading content and the infectious presentation form provide the students with better information access channels and platforms. But at the same time, it also puts forward higher requirements for reading literacy. The education and information management department of colleges and universities should help students to establish "big digital reading life view", guide students to integrate digital reading and daily life; and fully develop and utilize digital reading resources at home and abroad; and continuously expand the extension of students' reading and learning; promote the readers to gradually master the reading skills in the digital reading activities through the organization of educational and comprehensive digital reading activities, form a good reading habit and improve the digital reading literacy. The primary task to cultivate college students' digital reading literacy is to stimulate their interest in digital reading.

The university libraries and related educational departments should set up the campus digital reading service group in time, expand the digital sharing reading resources, and create a good campus culture atmosphere. At the same time, the information management department should also actively optimize the reading interface, build an interactive platform suitable for reading and making people willing to read, and create a digital interface with rich cultural background, concise and clean reading window, good user experience, enabling downloading and offline reading at any time, with both pictures and texts, appropriate in both dynamic and static state. This reading platform can stimulate readers' reading enthusiasm and interest in reading. Of course, in the process of creating a reading environment, attention should be paid to the deepening of cognitive activities and the supplement of association, the excavation of the content and essence of digital reading, the improvement of the reader's digital reading ability, and the improvement of the students' digital reading effect [6].

\section{CONCLUSIONS}

College students are the future builders of the country. In view of the characteristics of college readers, it is the responsibility and obligation of the universities to build various platforms and create a healthy and upward reading environment for college readers. Reading and promotion is a long way to go. Reading is endless. Start from me, start from now, make reading a living habit of every college student, make reading change life, and make the fragrance of books all around the campus.

\section{REFERENCES}

[1] Wang Peilin, Wang Wen. Study on Reading Habits of College Students under "Fragmentation Reading" [J], Henan Library Journal, 2018 (2): 90-92.

[2] National Library Research Institute. The fifteenth national reading survey results were released [J], National Library Science Journal, 2018 (3): 38 .

[3] Yu Xiangqian, Qu Hong, Lu Binlian. Analysis on Circulation Rules of Paper Books in University Libraries [J], Agricultural Network Information, 2018 (3): 69-71.

[4] Chen Yi, Wang Siwei, Miao Shouyan. Investigation and Research on the Current Situation of Contemporary College Students' Reading --- Taking Linyi University as an example, [J], Modern Communication, 2018 (8): 57-58.

[5] Duan Minmin. Statistical Analysis of Library Lending under the Network Environment [J], Knowledge Economy, 2014 (24): 21-23.

[6] Xie Lina. Research on the Cultivation Way of Digital Reading Literacy of College Students in the New Media Age [J], Neijiang Technology, 2018 (5): 108. 